\title{
Burden of Anemia and Hemoglobin Response to Iron Therapy in Adolescent Girls of State of Chhattisgarh
}

\author{
Authors

\section{Dr Abha Singh ${ }^{1}$, Dr Avinashi Kujur ${ }^{2}$, Dr Nalini Mishra ${ }^{3}$} \\ ${ }^{1}$ Director, Professor \& HOD, Department of Obs \& Gyne, Pt.J.N.M .Medical Collage, Raipur, Chhattisgarh \\ Email - asingh7612@gmail.com \\ ${ }^{2}$ Assistant Professor, Department of Obst \& Gyne, Pt.J.N.M. Medical Collage, Raipur, Chhattisgarh \\ Email-avinashikujur@gmail.com \\ ${ }^{3}$ Associate Professor, Department of Obst \& Gyne, Pt.J.N.M.Medical Collage, Raipur, Chhattisgarh \\ Email-mishranalini@gmail.com \\ Corresponding Author \\ Dr Avinashi Kujur \\ A-12, Maruti Residency, Amlidih, Raipur, Chhattisgarh \\ Email-avinashikujur@gmail.com
}

\begin{abstract}
Aims and objectives - To define the prevalence of anemia in the adolescent girls of state of Chhattisgarh and to study its epidemiological correlates and response to iron supplementation.

Material and methods - Total 4900 adolescent girls of 10-14 years attending various school were screened for anemia during period of one year. Anemic girls were supplemented with iron tablets for 90 days. The follow up hemoglobin was done after 3 months. Data was analyzed statistically.

Results - Prevalence of anemia in adolescent girls was 64\%. Significant epidemiological correlation were poverty, low BMI, worm infestation, poor hygiene and menorrhagia $(p<0.05)$. Response to 3 months iron therapy was observed in significantly high number (63\%) of subjects.

Conclusion - prevalence of anemia in adolescent girls of Chhattisgarh State was an alarming 64\%. It responded well to iron supplementation. There is an urgent need to create awareness to prevent short as well as long term morbidities in precious years of adolescence.
\end{abstract}

Keywords - Adolescent, anemia, menorrhagia, iron therapy.

\section{Introduction}

The world is marching ahead in the new millennium. Over half of the population of the world is under 25 years of age and more than three quarters of its youth live in the developing countries. The irony of nutritional anemia in the developing countries specially in girls and women remains a challenge to the society.
Global awareness of adolescent health issue drew attention in the International Year of Youth in 1985. Later in 1989, the World health Assembly focused on the same. Girls constitute a vulnerable lot, specially in countries like India where they are deprived of healthy diet, poor access to health services and early marriage which exposes them to a greater risk of reproductive morbidity and 
mortality. In this period of rapid growth if there is malnutrition, improper dietary habits and worm infestation, they are extremely vulnerable to all kinds of nutritional morbidities. Adolescence is the time of intense physical, psycho social and cognitive development. Increased nutritional demand at this juncture relates to the fact that adolescent gain up to $50 \%$ of their adult and skeletal mass during this phase. Anemia remains the biggest cause of school dropouts in India.

The Risk of Iron deficiency anemia appears during this growth spurt for both the girls as well as the boys but afterwards it continues for the girls because of the ongoing menstrual blood loss as well as frequent episodes of menorrhagia. This calls for the aptly described 'Red Alert' in the society. An initiative is being taken up by Indian Medical Association in this context as Movement Against Anemia.(MAA) ${ }^{2}$

Fortunately iron deficiency anemia is one of the important preventable problems and can be corrected to a considerable extent through school based anemia assessment, counseling and supplementation programmes. This measure can represent a real opportunity to make a difference in lifelong events. Adolescent Anemia Control Programme is an important milestone in this direction.

\section{Aims and objective}

The aim of the study was to define the prevalence of anemia, to study the epidemiological correlates of nutritional anemia, counseling and educating the adolescents and to verify the effect of iron supplementation in terms of improvement in the haemoglobin concentration in the state of Chhattisgarh.

\section{Material \& Method}

The present study "Burden of Anemia and Hemoglobin Response to iron Therapy in Adolescent Girls of the State of Chhattisgarh" Was conducted by the department of Osbtetrics and Gynaecology, Pt.J.N.M.Medical College and
Dr.B.R.A.Hospital, Raipur Chhattisgarh over one year period.

This was a prospective cross sectional study which included 4900 adolescent girls in the age of group of 10 to 14 years attending, government, private and municipal corporation schools of 6 districts of Chhattisgarh State namely Raipur. Bilaspur. Korba, Kanker, Janjgeer and kurud The list of school in the given district along with the permission to carry out the study was obtained from the respective District Education Officer. Informed consent of the Principal of the school was also taken and on the pre decided day the team consisting of doctors, technicians and interns visited the school.

A pre designed proforma in the form of questionnaire was used to collect the information regarding age, socio economic status, type of diet consumed, $\mathrm{H} / \mathrm{o}$ worm infestation, age of menarche, excessive menstrual bleeding during the last 3 months and symptoms suggestive of anemia viz weakness, lack of appetite, easy fatigability, dyspnoea, loss of concentration in the studies and syncopal attacks. Girls with know sickle cell anemia, chronic illness or receiving long term drugs were excluded from the study.

All the girls were then clinically examined for signs of anemia and vitamin deficiency. Their nutritional status was evaluated using WHO recommended age specific cut off points of body mass index. BMI of less then $5^{\text {th }}$ percentile for the particular age was the criteria used for classifying under nutrition. Hemoglobin estimation was done using Tallqvist Technique. Cut off point for hemoglobin level taken was as per WHO guidelines (Values $<12 \mathrm{gms} \%$ for adolescent girls) $\&$ severity of it was graded as mild (10-12 gm/dl), moderate $(7-10 \mathrm{gm} / \mathrm{dl})$ and severe $(<7 \mathrm{gm} / \mathrm{dl})$. Anemic girls were provided Iron tablets for 3 months. These were supplied by pharmaceutical companies \& NGOs. Simultaneous counseling of students was done regarding the dietary \& good hygiene. At the end of this visit, an educational session regarding prevention of anemia was 
organized in each school for the entire staff and students.

A follow up visit was done after 3 months by the same team \& the follow up haemoglobin assessment was done. Improvement in the grade of severity of anemia or achieving normal range of $\mathrm{Hb} \%$ was considered to be the significant improvement. Data was collected and epidemiological analysis was carried out by the frequency \& correlation analysis. Statistical significance was determined by Chi square test using the $\mathrm{P}$ value at the probability of 0.05 .

\section{Results}

A total of 4900 adolescent girls participated in the study. Anemia was diagnosed in 3136 (64\%) girls. Table-1 shows epidemiological correlates of both the anemic \& non anemic groups. Majority girls belonged to families with income group III in both the groups followed by grade IV in anemic group $(40 \%)$ with significant difference from non anemic group $(10.88)(\mathrm{P}-<0.005)$ in contrast, girls belonging to grade II were $30.66 \%$ in the later versus $15.65 \%$ in the anemic group $(\mathrm{P}<0.005)$.

A total of $693(22.09 \%)$ girls in the anemic group were undernourished $\left(\mathrm{BMI}<5^{\text {th }}\right.$ percentile) as compare to $158(8.95 \%)$ of their non anemic counterparts $(\mathrm{P}<0.05)$ Majority of the girls in both group were having BMI 5-85 percentile. Significantly more girls in the non anemic category had $\mathrm{BMI}>85$ percentile $(\mathrm{P}<0.005)$.

Statistically significant association was also observed between vegetarian diet, non hygienic conditions as well as worm infestation and anemia $(\mathrm{P}<0.05)$.

Overall 2493 girls attained menarche. Out of these $1908(60.84 \%)$ girls belonged to anemic group as compared to $585(33.16 \%)$ without anemia $(\mathrm{P}<0.05)$, further more among menstruating girls 1680 (80.20) anemic girls had menorrhagia against only $193(32.9 \%)$ girls of non anemic group $(\mathrm{P}<0.005)$.

The vast majority of anemic girls had one or the other predominant symptoms of anemia as compared to non anemic group where 1497 $(84.86 \%)$ girls were symptom free $(\mathrm{P}<0.001)$.

The overall prevalence of anemia among adolescent girls in our study was 64\% (table 2) Categorically the mild, moderate and severe anemia was found in $45.24,17.08 \& 1.6 \%$ subject respective.

Table-3 exhibits the prevalence of anemia in various study conducted in India from 1998 to $2007^{3-17}$ which ranges from $13-3 \%$ to $90.1 \%$. Our study results fall in between these with on overall prevalence of $64 \%$.

Although iron tablets were given to all anemic subjecta at the time of first visit, on follow up after 3 months a total of 2976 girls could be screened. Out of the remaining 160 girls. 118 were absent while 32 did not take the tablets due to nausea or constipation. Significant improvement in $\mathrm{Hb} \%$ was observed in 1983 (63.23\%) girls (Table-4) 


\section{JMSCR Vol.||03||Issue ||08||Page 7280-7287||August}

Table:-1 Epidemiological Determinants of anemia

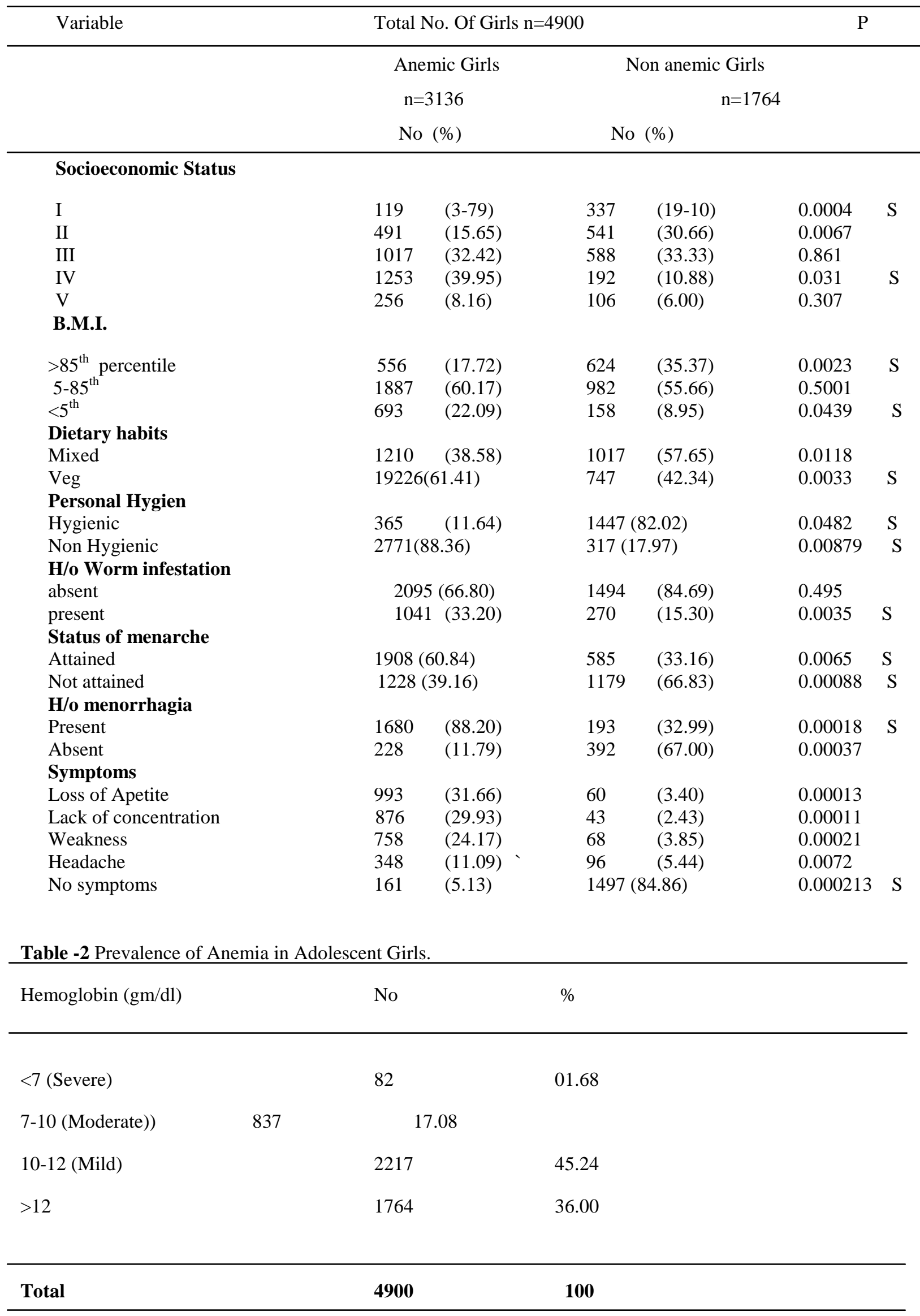


Table:-3 Prevalence of anemia adolescent girls in various Indian studies:-

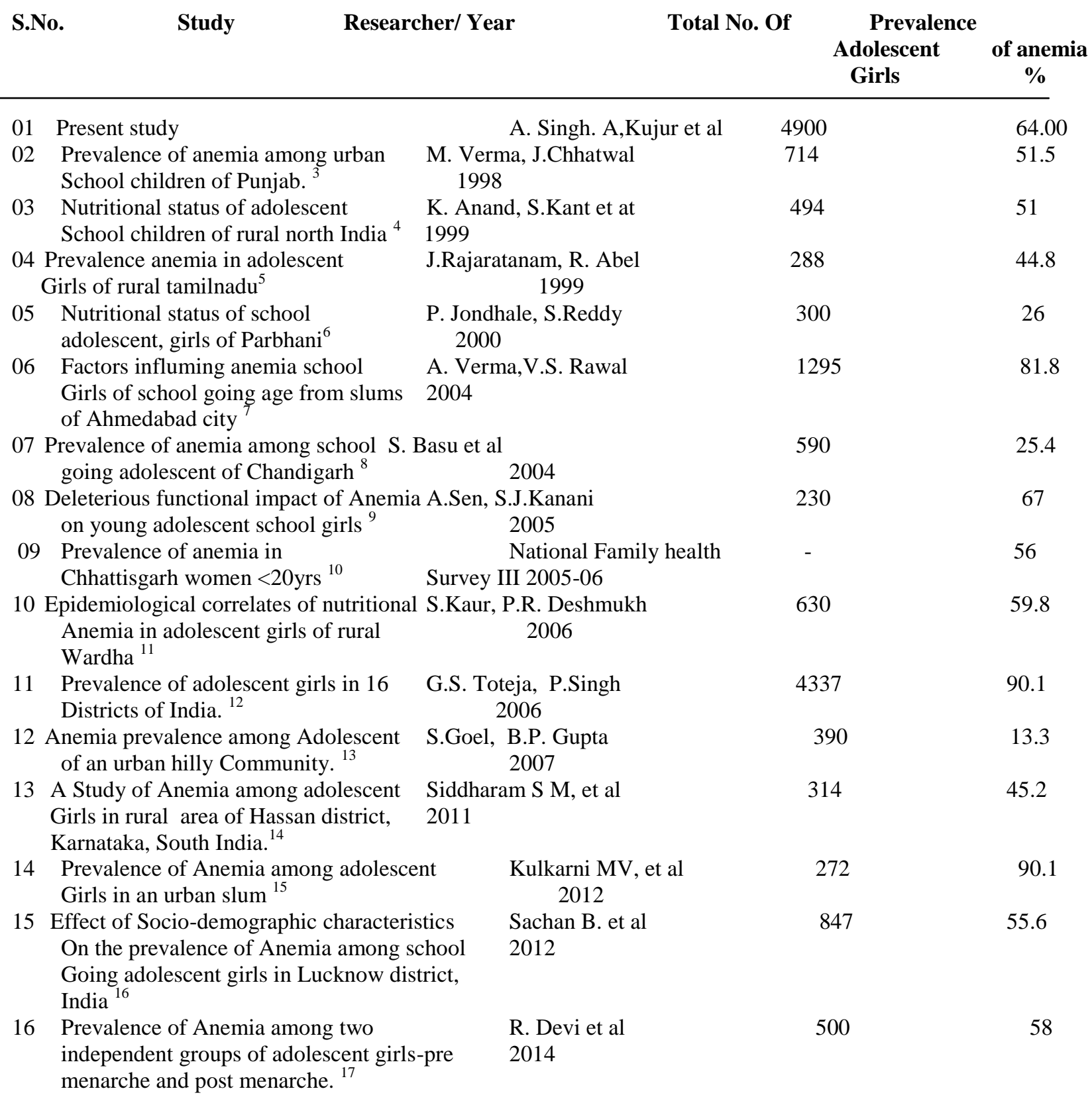

Table 4: Improvement in $\mathrm{Hb}$ level after iron therapy

Total No of anemic Girls $n=3136$

No

3136

2976

Follow up after 3 months

1983

160

Students lost to follow up \& non compliance
(\%) 


\section{Discussion}

As per our anticipation, the prevalence of anemia among adolescent girls was found to be quite high i.e. $64 \%$ in our state and the important correlates of anemia were found to be poverty (Socioeconomic grade IV or above) low BMI, vegetarian diet, post menarche status. Worm infestation and menorrhagia.

Although majority of girls in both anemic as well as non anemic group were from middle income group, the levels of haemoglobin decreased with deteriorating economical status. Apparently the overall household income directly affects the quality of diet, nutritional status and hygiene adversely. Jhondale et al ${ }^{7}$ and B. Sachan ${ }^{16}$ reported the incidence of anemia to be maximum in the poorer sections of the society. In the study by $\mathrm{S}$.Kaur et al ${ }^{11}$, the girls with grade $\mathrm{V}$ status were associated with increased likelihood of anemia (O.R. 3.87). Higher prevalence of anemia among girls with vegetarian diet may be due to lower bio-availability of iron especially in the cereal based diet compounded by phytates \& oxalates present in the green leafy vegetables. This observation is of paramount importance since rice is the staple diet of this state which is mostly consumed with one of the leafy vegetables.

Worm infestation in the adolescent with the rapid growth related nutritional demand may contribute to a considerable extent in the occurrence and magnitude of anemia.

More girls were anemic after achieving menarche. This could be due to the consequent blood loss in menses with resultant fall in haemoglobin. The prevalence of anemia increased even in girls with history of menorrhagia, this observation is in conformity with other studies $3,11,13,15,17,20$ and emphasizes the urgent need for preventive and corrective measures for anemia in girls before they attain menarche so as to compensate for the extra demands for growth and development during their forthcoming growth spurt of as well as to take care of the losses incurred during episodes of menorrhagia.
The prevalence of anemia in adolescent girls was $64 \%$ in our study which is higher than the reported incidence of $56 \%$ by NFHS $111^{10}$. The present study included a large no of subjects from various strata of society and schools and therefore represents a wider population. Amongst other studies conducted in India from 1998 to 2007 the incidence varied from $13.3 \%$ to $91.1 \%$. The wide difference in the prevalence may be attributed to the difference in the area studies e.g.S. Goel et $\mathrm{al}^{13}$ reported the lowest prevalence of $13.3 \%$ in Urban Hilly Community \& commented about the reason being the higher altitude. However NHFS II has reported a prevalence of $56 \%$ among adolescents in Himanchal Pradesh. This disparity may be solved by planning further comparative studies in hilly verses plain areas.

WHO/UNICEF has suggested that the problem of anemia is very high in a community when the prevalence exceeds $40 \%$. In this view our prevalence of $64 \%$ should be considered serious and calls for alert as well as corrective measures. Fortunately in present study maximum girls with anemia had mild and moderate degree $(45.24 \%$ and $17.08 \%$ ) respectively with severe anemia found in $1.6 \%$ in girls only. Others ${ }^{7,11,12}$ have also made the similar observation. Since mild and moderate anemia can be effectively treated with oral therapy, we availed the opportunity of distributing iron and folic acid tablets to anemic girls at the time of screening itself. On the follow up visit after 3 months the improvement in the haemoglobin level was achieved in $63.23 \%$ subjects. This is in agreement with S.Mehnaz et al ${ }^{18}$ K.N.Agrawal et $\mathrm{al}^{19}$ compared the benefits of anemia prophylaxis by weekly versus daily supplementation of iron, folic acid \& concluded that daily dose schedule was superior in terms of early rise in the haemoglobin status. The significant achievement during the precious years of adolescent can prevent them from spoiling their growth, physical work capacity \& cognition. This drive will also have its long term advantages in preventing reproductive morbidity and mortality later on in life. 
Although improving iron status is addressing only one facet of the bigger problem of generalized malnutrition of adolescent. It should be coupled with dietary modification and deworming.

Conclusion \& Recommendation - In the screening of 4900 adolescent school girls of Chhattisgarh, prevalence of anemia was found to be $64 \%$. This is alarming because of its negative implications on their growth, physical capacity and cognitive functions in the short term and reproductive morbidity in the long term. The association of anemia was established with poor nutrition and hygiene, worm infestation and after menarche. Fortunately majority of the girls had mild and moderate degree of anemia which responded significantly to iron folic acid supplementation over a 3 months period. During the course of the project, our experience was that creating awareness was not only important in the students, but more so for teachers who would be able to understand their students better if they knew the symptoms of anemia well. They are the best motivators for taking corrective measures. We therefore suggest that the health care system should avail the opportunity of supplying deworming drugs, improving sanitation, spreading awareness regarding proper dietary habits, deworming and fortification of common food items.

The present study highlights the urgent need of pragmatic interventions programmes to improve hemoglobin status of the adolescent girls and join hands in the Movement Against Anemia (MAA) with a strong will and determination that "We will do it"

Acknowledgement: We are thankful to all the District Education Officers and Principals and Teachers of various school of 6 districts of Chhattisgarh State for their kind co-operation and active support. We would also like to thank the consultants, junior doctors. Medical students and technicians for carrying out the immense task so smoothly but with dedication. Special thanks to
Merck Pharmaceuticals Company for providing free samples of iron tablets.

\section{References}

1. Mehra S. Agarwal D. Adolescent health determinants for pregnancy and child health outcomes among the urban poor. India Pediatrics 2004;42:137-145.

2. Ahmed M, Gaash B, Kadir S M. Movement against anemia (MAA) (an initiative of the India Medical Association) Indian Journal for the practicing doctor 2005; 2, (5):11-12.

3. Verma M, Chhatwal J, Kaur G. Revalence of anemia among urban school children of Punjab. Indian Pediatr 1998;35:1181-1186.

4. K.Anand, S.Kant, KapoorS.K.Nutritional state of adolescent school children in rural North India. Rural health services project 1999.

5. Rajaratnam J, J.S.Asokan, Parul Jonathan. Prevalence of anemia among adolescent girls of rural Tamilnadu. India Pediatrics 2000;37:532-536.

6. NFHS III: -NFHS-2, 2005-2006 and National monitoring bureau survey (NNMBS), 2006.

7. Jondhale J.P, Reddy S, VijayaN.A, Nalwade M. Nutritional status of school going adolescent girls of Parbani. Ind.J.Nutr.Dietet 2000;38:262-267

8. Verma A, Rawal V.S, Kedia G, Kumar D, Chauhan J. Factors influencing anemia among girls of school-going age from the slums of Ahmedabad City. Indian Journal of community Medicine 2004;29:01-03.

9. Basu S, Basu S, Hazarika R, Parmar V. Prevalence of anemia among school going adolescents of Chandigarh. Indian paediatrics 2005;42:593-597

10. Sen A, Kanani S J. Deleterious functional impact of anemia on young adolescent school girls. Indian Pediatrics 2006;43:219-226 
11. Kaur S. Deshmukh PR, Garg B S. Epidemiological correlates of nutritional anemia in adolescent girls of rural Wardha. 2006;31(4): 10-12

12. Toteja G S, Singh P, Dhillon B S, Saxena B N, Ahmed F U, Singh R P et al. Prevalence of anemia among pregnant women and adolescent girls in 16 districts of India. Food and Nutrition Bulletein 2006;27(4):311-315

13. Goel S.Gupta B P. Low anemia prevalence among adolescent of an urban hilly community. Indian Journal of Community Medicine 2007;32(1):01-03

14. Siddharam SM, Ventetesh GM , Thejeshwari H L. A Study of Anemia Among Adolescent Girls in Rural Area of Hassan district Karnataka South India. Int Biol Med Res. 2011;2(4):922-924

15. Kulkarni MV, Durge P M, Kasturwar N B, Prevalence of Anemia Among Adolescent Girls in an Urban slum. NJCM 2012;3 (1) : 108-111

16. Sachan B, Idirs M Z, Singh A. Effect of Socio demographic characteristics on the prevalence of anemia among school going adolescent girls in lucknow distric, India. South East Asia Journal of Public Health 2012;2(1):8-12

17. Devi R, Jaysree T M, Felix J W, Ethirajan N. Prevalence of Anemia among two independent groups of adolescent girls pre menarche and post menarche. Journal of Drug Discovery amd Therapeutics 2014; 2(23) : 04-07

18. Mehnaz S, Afzal S, Khalil S, Khan Z, et al Indian Journal of Community Medicine. 2006;31(3):07-09

19. Agarwal K N, Gomber S, Bisht H, Som M. Anemia prophylaxis in adolescent school girls by weekly or daily iron-folate supplementation. Indian Pediatrics 2003;4:296-301

20. Gupta A, Parashar A, Thakur A, Sharma D. Anemia among adolescent girls in
Shimla Hills of North India :Does BMI and Onset of Menarche have a Role? Indian Journal of Medical Sciences 2012; 66 (5); 126-130. 